\section{BRAZIULIAN JOURNAL}

OF MEDICAL AND BIOLOGICAL RESH ARCH

www.bjournal.com.br
ISSN 0100-879X

Volume 43 (03) 226-324 March 2010

BIOMEDICAL SCIENCES

AND

CLINICAL INVESTIGATION

Braz J Med Biol Res, March 2010, Volume 43(3) 234-241

Proteoliposomes as matrix vesicles' biomimetics to study the initiation of skeletal mineralization

A.M.S. Simão, M.C. Yadav, P. Ciancaglini and J.L. Millán

The Brazilian Journal of Medical and Biological Research is partially financed by
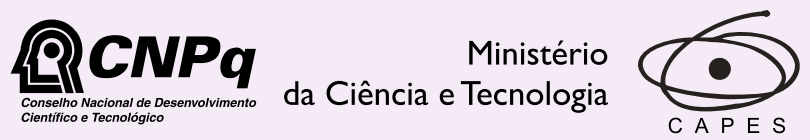

Ministério da Educação

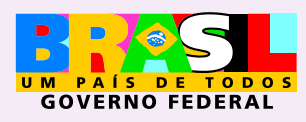

Institutional Sponsors 


\title{
Proteoliposomes as matrix vesicles' biomimetics to study the initiation of skeletal mineralization
}

\author{
A.M.S. Simão ${ }^{1,2}$, M.C. Yadav ${ }^{1}$, P. Ciancaglini ${ }^{2}$ and J.L. Millán ${ }^{1}$ \\ ${ }^{1}$ Sanford Children's Health Research Center, \\ Sanford-Burnham Medical Research Institute, La Jolla, CA, USA \\ 2Departamento de Química, Faculdade de Filosofia, Ciências e Letras de Ribeirão Preto, \\ Universidade de São Paulo, Ribeirão Preto, SP, Brasil
}

\begin{abstract}
During the process of endochondral bone formation, chondrocytes and osteoblasts mineralize their extracellular matrix by promoting the formation of hydroxyapatite (HA) seed crystals in the sheltered interior of membrane-limited matrix vesicles (MVs). Ion transporters control the availability of phosphate and calcium needed for HA deposition. The lipidic microenvironment in which MV-associated enzymes and transporters function plays a crucial physiological role and must be taken into account when attempting to elucidate their interplay during the initiation of biomineralization. In this short mini-review, we discuss the potential use of proteoliposome systems as chondrocyte- and osteoblast-derived MVs biomimetics, as a means of reconstituting a phospholipid microenvironment in a manner that recapitulates the native functional MV microenvironment. Such a system can be used to elucidate the interplay of MV enzymes during catalysis of biomineralization substrates and in modulating in vitro calcification. As such, the enzymatic defects associated with disease-causing mutations in MV enzymes could be studied in an artificial vesicular environment that better mimics their in vivo biological milieu. These artificial systems could also be used for the screening of small molecule compounds able to modulate the activity of MV enzymes for potential therapeutic uses. Such a nanovesicular system could also prove useful for the repair/treatment of craniofacial and other skeletal defects and to facilitate the mineralization of titanium-based tooth implants.
\end{abstract}

Key words: Alkaline phosphatase; Biomineralization; Calcification; Lipids; Pyrophosphate; ATP

\section{Matrix vesicles}

Mineralization of cartilage and bone occurs by physicochemical and biochemical processes that facilitate the deposition of hydroxyapatite (HA) in specific areas of the extracellular matrix (ECM). Experimental evidence has pointed to the presence of HA crystals along collagen fibrils in the ECM (reviewed in Ref. 1) and also within the lumen of chondroblast-and osteoblast-derived matrix vesicles (MVs) (reviewed in Ref. 2). Investigators in the bone mineralization field are usually divided in supporting the collagen- versus the MV-mediated mechanism of mineralization, but we see no incompatibility between these mechanisms. Our working model is that bone mineralization is first initiated within the lumen of MVs and, in a second step, HA crystals grow beyond the confines of the MVs and become exposed to the extracellular milieu where they continue to propagate along collagen fibrils. This process is coordinated by the balanced action of promoters and inhibitors of calcification (reviewed in Ref. 3).

It is currently believed that MVs have at least two principal roles in initiating calcification: 1) MV enzymes regulate the ratio of phosphate $\left(\mathrm{P}_{\mathrm{i}}\right)$ to inorganic pyrophosphate $\left(\mathrm{PP}_{\mathrm{i}}\right)$ in the intra- and extravesicular fluid, and 2) MV proteins and lipids, including acidic phospholipids, serve as nucleation sites for apatite deposition (4). $\mathrm{PP}_{\mathrm{i}}$, derived both from ectoplasmic PC-1/nucleotide pyrophosphatase/phosphodiesterase-1 (NPP1)-catalyzed production from extracellular nucleoside triphosphates (5) and by intracellular export via the ankylosis protein (ANK) transporter, inhibits matrix mineralization (6). This inhibition is released through the action of tissue-nonspecific alkaline phosphatase (TNAP), which hydrolyzes $\mathrm{PP}_{\mathrm{i}}$, thus simultaneously removing the inhibitor and providing additional $\mathrm{P}_{\mathrm{i}}$ for mineral formation $(7,8)$. Mineralization is said to proceed in two phases: an initial formation of apatite within MVs, and a subsequent

Correspondence: J.L. Millán, Sanford Children's Health Research Center, Sanford-Burnham Medical Research Institute, 10901 North Torrey Pines Road, La Jolla, CA 92037, USA. Fax: +1-858-646-3195. E-mail: millan@burnham.org

Received December 12, 2009. Accepted February 5, 2010. Available online February 19, 2010. Published March 12, 2010. 
propagation phase in the matrix $(2,9)$. According to this mechanism, $\mathrm{Ca}^{2+}$ enters MVs via an annexin channel and phosphate enters via a type III $\mathrm{Na}^{+}$-dependent phosphate transporter $\left(\mathrm{P}_{\mathrm{i}} \mathrm{T}\right)$, and possibly other $\mathrm{P}_{\mathrm{i}}$-transporters, to form apatite within MVs $(10,11)$. Acidic phospholipids and other MV components are thought to nucleate these intravesicular nanocrystals (12-14). Subsequently, the intravesicular mineral grows beyond the confines of MVs onto a collagenous matrix aided by a number of promoters and inhibitors of calcification (3).

\section{MV enzymes, channels and transporters}

MVs are complex nanovesicles. Three recent proteomic papers have provided a first indication of just how diverse their proteomic constitution is (15-17). Here we will only refer to some of the enzymes, channels and transporters that have been implicated in the biological function of MVs to date. Figure 1 illustrates the proposed role of the molecules that are described in more detail below.

TNAP is the only tissue-nonrestricted isozyme of a

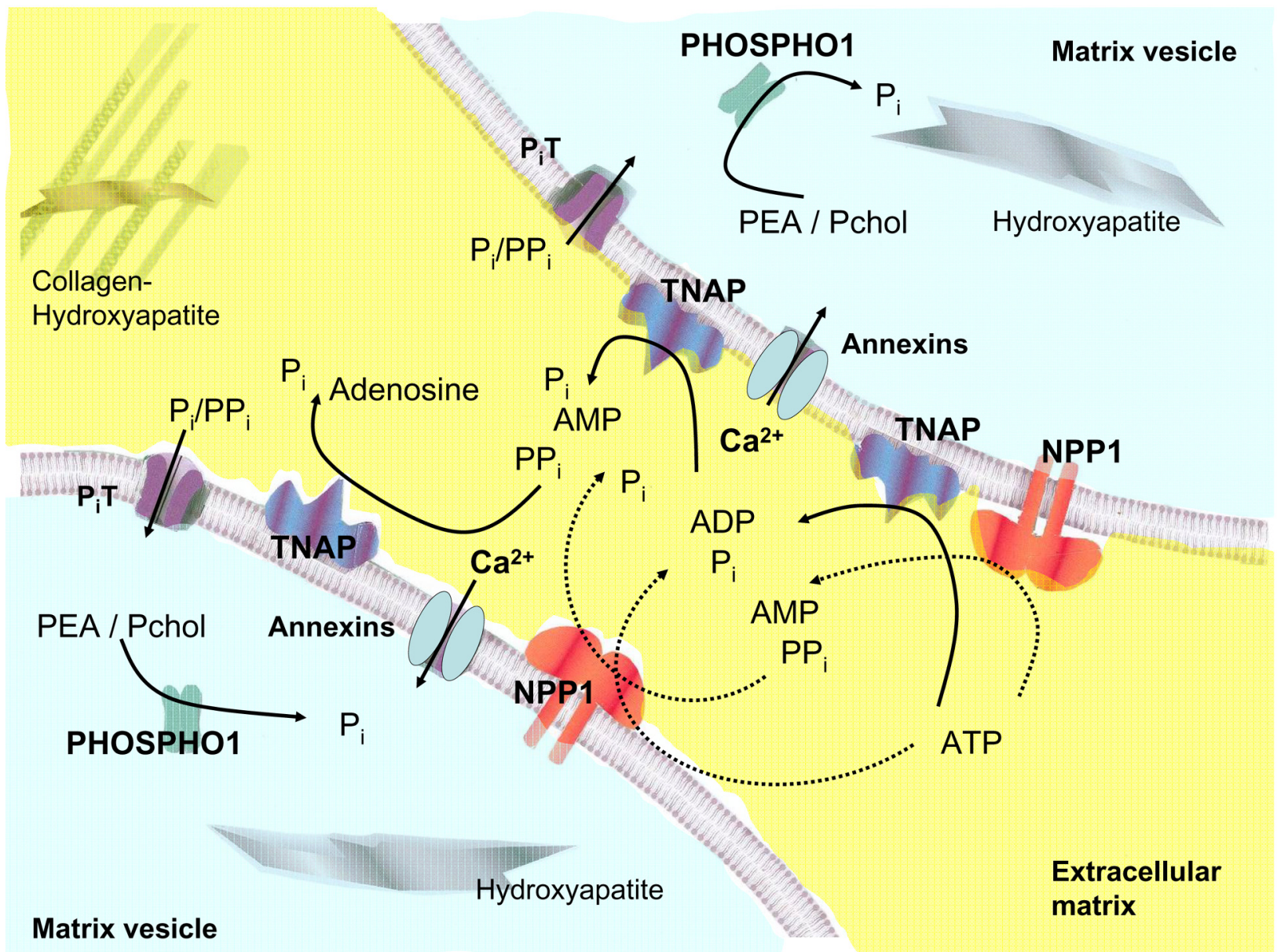

Figure 1. Schematic representation of the molecules involved in matrix vesicle (MV)-mediated calcification including the most favored enzymatic reactions of their putative physiological substrates. This is a modified figure based on the one published in Ciancaglini et al. (54). Hydroxyapatite seed crystals are formed in the sheltered interior of MVs favored by the inorganic phosphate $\left(\mathrm{P}_{\mathrm{i}}\right)$-generating ability of PHOSPHO1, which uses phosphocholine (Pcho) and phosphoethanolamine (PEA) as substrates, as well as by the function of $\mathrm{P}_{\mathrm{i}}$-transporters $\left(\mathrm{P}_{\mathrm{i}} \mathrm{T}\right)$ and annexins that mediate $\mathrm{Ca}^{2+}$ ion influx. Tissue-nonspecific alkaline phosphatase (TNAP) has a major role both as a PPiase and as an ATPase/ADPase and thus participates in the calcification process by restricting the concentration of extracellular $\mathrm{PP}_{\mathrm{i}}$ while also contributing to the $\mathrm{P}_{\mathrm{i}}$ pool available for calcification. PC-1/nucleotide pyrophosphatase phosphodiesterase 1 (NPP1) can act as a backup PPiase and also ATPase, particularly in the absence of TNAP. Thick lines indicate the most favored reactions, while dotted lines indicate alternative backup enzymatic reactions. Outside the MVs, collagen acts as a primary scaffold for the deposition of hydroxyapatite crystals. 
family of four homologous human AP genes (EC. 3.1.3.1) (reviewed in Ref. 18). Expressed as an ecto-enzyme anchored via a phosphatidylinositol glycan moiety, TNAP has been demonstrated to play an essential physiological role during bone matrix mineralization. A deficiency in the TNAP isozyme causes the inborn error of metabolism known as hypophosphatasia and the study of this disease has provided the best evidence of the importance of TNAP for bone mineralization (19). The severity of hypophosphatasia is variable and is modulated by the nature of the TNAP mutation $(18,19)$. The clinical severity of hypophosphatasia patients varies widely. The different syndromes, listed from the most severe to the mildest forms, are: perinatal hypophosphatasia, infantile hypophosphatasia, childhood hypophosphatasia, adult hypophosphatasia, odontohypophosphatasia, and pseudohypophosphatasia (19). These phenotypes range from complete absence of bone mineralization and stillbirth to spontaneous fractures and loss of decidual teeth in adult life. Inactivation of the mouse TNAP gene (Akp2) phenocopies the infantile form of human hypophosphatasia (18). Biochemically, hypophosphatasia is diagnosed by a low serum TNAP level as well as accumulation of the phosphocompounds inorganic pyrophosphate $\left(\mathrm{PP}_{\mathrm{i}}\right)$, pyridoxal-5'-phosphate and phosphoethanolamine (PEA) $(18,19)$.

In bone, TNAP is confined to the cell surface of osteoblasts and chondrocytes, including the membranes of their shed MVs (2). It has been proposed that the role of TNAP in the bone matrix is to generate the inorganic phosphate needed for HA crystallization. However, TNAP has also been shown to hydrolyze the mineralization inhibitor $\mathrm{PP}_{\mathrm{i}}$, thus facilitating mineral precipitation and growth (2). Electron microscopy revealed that TNAP-deficient MVs, in both humans and mice, contain apatite crystals, but that extravesicular crystal propagation is delayed $(20,21)$. This growth retardation could be due to either the lack of TNAP's pyrophosphatase function or the lack of inorganic phosphate generation. Our recent studies have provided compelling proof that the major function of TNAP in bone tissue consists of hydrolyzing $\mathrm{PP}_{\mathrm{i}}$ to maintain a proper concentration of this mineralization inhibitor to ensure normal bone mineralization $(7,8,22)$.

A primary inhibitor of ECM mineralization is extracellular $\mathrm{PP}_{\mathrm{i}}(23)$, primarily generated by the members of the nucleotide pyrophosphatase/phosphodiesterase (NPP) family of isozymes. Nucleotide pyrophosphatase/phosphodiesterase-1 (NPP1) is plasma membrane-bound, whereas autotaxin (NPP2) is secreted and B10 (NPP3) is abundant in intracellular spaces (5). All three isozymes are expressed in a wide variety of tissues, including bone and cartilage and they all share the ability to hydrolyze diesters of phosphoric acid into phosphomonoesters, primarily ATP to AMP and $P P_{i}$, and/or ADP to adenosine (5). Similar to skeletal TNAP expression, NPP1 is highly abundant on the surfaces of osteoblasts and chondrocytes as well as on the membrane of their MVs (5). NPP1 has a role in inhibiting $\mathrm{HA}$ precipitation by its $\mathrm{PP}_{\mathrm{i}}$-generating property (5).

Similar to NPP1, ANK has a role in mineralization by contributing to the extracellular supply of $\mathrm{PP}_{\mathrm{i}}$. However, unlike NPP1, ANK appears to function as a transmembrane $\mathrm{PP}_{\mathrm{i}}$-channeling protein, allowing $\mathrm{PP}_{\mathrm{i}}$ molecules to pass through the plasma membrane from the cytoplasm to the outside of the cell (6). ANK protein is detectable in many tissues, yet its expression is particularly strong in the cartilage of joints (6). Cell surfaces of osteoblasts and chondrocytes appear to be abundant in ANK protein.

Mice deficient in NPP1 (Enpp1/-) or ANK (ank/ank) develop soft tissue calcification, including vascular calcification, resulting from the reduced production or transport of $\mathrm{PP}_{\mathrm{i}}(7,8,22)$, while mice deficient in TNAP function $\left(\mathrm{Akp}^{-/-}\right)$ display rickets and osteomalacia due to an arrest in the propagation of HA crystals outside the MVs caused by an increase in extracellular $\mathrm{PP}_{\mathrm{i}}$ concentrations $(2,7,8,21)$. HA crystals are still present in TNAP-deficient MVs and it has been proposed that the soluble MV phosphatase $\mathrm{PHOSPHO} 1$ might be involved in increasing the local intravesicular concentration of $\mathrm{P}_{\mathrm{i}}$ to change the $\mathrm{P}_{\mathrm{i}} / \mathrm{PP}_{\mathrm{i}}$ ratio to favor precipitation of HA seed crystals (24).

$\mathrm{PHOSPHO} 1$ is a member of the haloacid dehalogenase superfamily of $\mathrm{Mg}^{2+}$-dependent hydrolases, first identified in chick embryos, that is expressed at levels 100 -fold higher in mineralizing chondrocytes than in non-mineralizing tissues and shows high phosphohydrolase activity towards PEA and phosphocholine (PCho) (25). The use of small compounds to inhibit its activity in $A k p 2^{-/-}$MVs leads to a significance decrease in in vitro MV-mediated calcification (24), implicating PHOSPHO1 function in the initiation of skeletal calcification. Since PHOSPHO1 is specific for PEA and $P C h o(24,25)$, it is possible that $P_{i}$ is generated from $\mathrm{PEA}$ and $\mathrm{PCh}$ through the enzymatic action of $\mathrm{PHOSPHO} 1$ during the mineralization process in order to generate the $\mathrm{P}_{\mathrm{i}}$ concentration needed to establish a $\mathrm{P}_{\mathrm{i}} / \mathrm{PP}_{\mathrm{i}}$ ratio permissive for the initial formation of HA crystal inside the MVs. The very low $\mathrm{K}_{\mathrm{m}}$ values for both PEA and PCho (3 and 11.4 $\mu \mathrm{M}$, respectively) (25) suggest that under physiological conditions both molecules would be rapidly hydrolyzed by $\mathrm{PHOSPHO} 1$, indicating that these compounds are therefore likely to be natural substrates of the enzyme.

Annexins also play an important role in MV function (26-28). Annexins are $\mathrm{Ca}^{2+}$ and phospholipid binding proteins, which under the right conditions can form calcium channels through MV membranes (26). These conditions include membranes with a high content of acidic phospholipids (26). MVs contain annexins II, V and VI, and in such membranes, MV annexins appear to be associated with $\mathrm{Ca}^{2+}$ transport. Moreover, annexin $\mathrm{V}$ binds to type II and $\mathrm{X}$ collagen and these interactions stimulate its $\mathrm{Ca}^{2+}$ channel activities leading to increased influx of $\mathrm{Ca}^{2+}$ into liposomes and matrix vesicles $(20,28)$.

The inorganic phosphate $\left(\mathrm{P}_{\mathrm{i}}\right)$ transporter $\left(\mathrm{P}_{\mathrm{i}} \mathrm{T}\right)$ fam- 
ily comprises $\mathrm{Na}^{+}$-dependent $\mathrm{P}_{\mathrm{i}}$ symporters, e.g., the mammalian type III NaP $\mathrm{P}_{\mathrm{i}}$ symporters, $\mathrm{P}_{\mathrm{i}} \mathrm{T} 1$ and $\mathrm{P}_{\mathrm{i}} \mathrm{T} 2$ (29). Moreover, the broad tissue distribution of $\mathrm{P}_{\mathrm{i}} \mathrm{T} 1$ and $\mathrm{P}_{\mathrm{i}} \mathrm{T} 2$ together with their transport characteristics suggests that they constitute the housekeeping phosphate uptake system between cells and the extracellular fluid (29). In addition, they have been implicated in chondroblastic and osteoblastic mineralization (30) as well as in transdifferentiation of vascular smooth muscle cells to osteoblast-like cells in the process of vascular calcification under hyperphosphatemic conditions (3). Despite the essential role of $\mathrm{P}_{\mathrm{i}}$ for life and the specific roles of $\mathrm{P}_{\mathrm{i}} \mathrm{T} 1$ and $\mathrm{P}_{\mathrm{i}} \mathrm{T} 2$ in supplying mammalian cells with their general $P_{i}$ needs as well as the increasing evidence for the role of type III transporters in normal and pathologic calcification, only a few studies have addressed the physiologic function of members of the $\mathrm{P}_{\mathrm{i}} \mathrm{T}$ family. Recently, Festing et al. (31) successfully generated conditional and null PiT1 mouse alleles to determine the in vivo role of $\mathrm{P}_{\mathrm{i}} \mathrm{T}$, and demonstrated that $\mathrm{P}_{\mathrm{i}} \mathrm{T} 1$ is necessary for embryonic development and is non-redundant, since $\mathrm{P}_{\mathrm{i}} \mathrm{T} 2$ could not compensate for the loss of $\mathrm{P}_{\mathrm{i}} \mathrm{T} 1$ and allow development into adulthood. Other studies have indicated that $\mathrm{P}_{\mathrm{i}}$ transporters other than $\mathrm{P}_{\mathrm{i}} \mathrm{T} 1 / 2$ might be involved in endochondral ossification (11).

\section{Lipid composition of MVs}

In order to understand the physiological interplay between important MV-associated enzymes in the initiation of biomineralization, it is important to keep in mind the microenvironment in which these enzymes function, which can have a profound effect on their biological properties, since phospholipids play an important role in the initiation of the biomineralization process $(4,20)$. Early studies of MV lipid composition have determined that there are significant differences between the lipid content of MVs and the plasma membranes from which they arose. Wuthier (32) reported these differences and hypothesized that the increase in acidic phospholipids in MVs was somehow associated with MV calcification. Further studies from his group, along with those of Boyan et al. (33) have proposed that MV lipids could act as a nucleation site for HA formation $(27,34,35)$. This premise has been extensively developed under the idea of a "nucleational core complex", which describes the interactions of MV phospholipids, $\mathrm{Ca}^{2+}, \mathrm{PO}_{4}{ }^{3-}$ and some MV proteins to form a molecular architecture that nucleates apatite crystallization $(27,36)$. The acidic phospholipids can bind $\mathrm{Ca}^{2+}$ but, more importantly, it has been shown that they facilitate calcium-dependent annexin binding, and are permissive for annexins to form calcium channels through the membrane $(12,26)$. Several lines of evidence suggest that glycosylphosphatidylinositol (GPI)-anchored proteins are commonly found to be enriched within putative cholesterol- and (glyco)sphingolipid-enriched platforms called "rafts" and that such association is required for the expression of their biological function $(37,38)$.

\section{Liposome systems}

Recent data (39) suggest that the location of TNAP on the membrane of MVs plays a role in determining substrate selectivity in this micro-compartment. These data suggest that assays of TNAP bound to MVs or to liposome-based systems might be more biologically relevant than assays done with solubilized enzyme preparations, particularly when studying the hydrolysis of organophosphate substrates. The ability of synthetic or natural vesicles $(40,41)$ to mimic the organizational structure and function of biomembranes makes these structures an advantageous and convenient experimental model to help in advancing our understanding of MV-mediated calcification. Table 1 lists some advantages and disadvantages of working with liposome systems when compared to the use of native MVs. While MVs represent the native nanovesicular system

Table 1. Comparison of the advantages and disadvantages of the use of proteoliposomes as biomimetics for matrix vesicles in the study of mechanisms of initiation of skeletal mineralization.

\begin{tabular}{lll}
\hline System & Advantages & Disadvantages \\
Matrix vesicles & Native membrane structure & Variable size \\
& Native protein composition & Undefined proteomic composition \\
& Relatively stable & Need live animals for isolation \\
& & Laborious isolation procedure \\
Proteoliposomes & Easy to prepare & Artificial system \\
& Controlled lipid composition & Limited stability \\
& Controlled reconstitution of proteins & \\
& Uniform size & \\
& Controlled electrolytes & \\
\hline
\end{tabular}


with a full complement of active proteins, their isolation demands the use of animals and a laborious procedure that can lead to the production of membrane artifacts in the process. In addition, the proteomic composition of these MVs is still incompletely defined, although some proteomic studies have recently been published (15-17). On the other hand, proteoliposomes are easy to prepare and can be manufactured using different methods and with controlled lipid and protein composition, electrolytes and sizes, representing a convenient experimental model to mimic the organizational structure and function of natural biomembranes and to reproduce some essential features of the biomineralization process $(42,43)$. But since proteoliposomes are artificial systems, it is important to consider also the stability of the vesicles, which may affect the structure and function of the reconstituted enzymes. An important experimental consideration is the need to establish the appropriate lipid composition, especially the cholesterol content, to be used in the construction of the proteoliposomes since the amount of cholesterol modulates the fluidity of the bilayer and influences membrane features, such as curvature, that can affect the activity of the enzymes in different ways, depending on the substrates used (40). Moreover, the lipid membrane plays an important role as a nucleation agent in the biomineralization process $(44,45)$, as a protective and/or activation agent (46).

Proteoliposomes can be obtained by different preparation techniques, such as mechanical dispersion, sonication, extrusion, solvent dispersion, co-solubilization with detergents and reverse-phase evaporation as well as direct insertion after removal of the detergent $(47,48)$. In fact, enzyme reconstitution varies depending on the methodology used for enzyme extraction, detergent used, solubilization method and also an adequate proportion of the lipids used (49-51). The method of first forming mixed micelles of various lipids and detergent followed by the use of appropriate resins to remove the detergent has proved to be an effective means to consistently synthesize homogeneous, unilamellar vesicles containing transmembrane proteins and with large encapsulated volumes (52). In this case, it is important to have the protein reconstituted with the right orientation in the membrane, since a random orientation would confound the design and interpretation of experiments aimed at elucidating the biological role of these proteins in the initiation of calcification (52). The method of direct insertion is more useful for proteins containing GPI anchors, since it allows the reconstitution of the enzymes into preformed liposomes by direct insertion of the anchor into the system. Acombination of both liposome methodologies could be used for the construction of more complex systems containing different types of proteins, with the co-solubilization method being used for the incorporation of transmembrane and cytosolic proteins, while the GPI-anchored proteins could then be integrated into this preformed system by direct insertion of the anchor portion of the molecule.
Two of the main lipids found in the MV membranes are dipalmitoylphosphatidylserine and dipalmitoylphosphatidylcholine (DPPC) and many studies have revealed that they play a crucial role in the biomineralization process, regulating both calcium entry into the MVs and formation of HA crystals $(4,26)$. Using the direct insertion method and DPPC liposomes, Simão et al. (53) described the production and characterization of proteoliposomes harboring TNAP alone, NPP1 alone and TNAP + NPP1 together as MV biomimetics to further understand the interplay between these enzymes in the utilization of physiological substrates as a means of understanding the more complex interplay of these enzymes in intact MVs, crucial during early events of skeletal mineralization. The data show that MV enzymes can be reconstituted into liposomes of predefined composition. Such proteoliposomes proved to be useful in the study of the kinetic interplay of two enzymes present together on biomembrane mimetics when presented with physiological substrates relevant to the biomineralization process. These studies were validated by simultaneous studies on isolated MVs. Thus, Ciancaglini et al. (54) examined substrate utilization by isolated osteoblast-derived MVs, where these and other enzymes are present together in a physiological biological compartment, reporting the relative ability of wild-type MVs, as well as MVs deficient in TNAP, NPP1 or PHOSPHO1 to utilize the substrates ATP, ADP and $\mathrm{PP}$ under physiological conditions. TNAP- and PHOSPHO1deficient MVs showed reduced calcification ability, while NPP1-deficient MVs hypercalcified, demonstrating that the cooperativity as well as the competition of TNAP, NPP1 and $\mathrm{PHOSPHO} 1$ for the biomineralization substrates provides an additional level of regulation of metabolite flow for the control of the calcification process.

The size of natural osteoblast- and chondrocyte-derived MVs varies from 20 to $300 \mathrm{~nm}$ in diameter and it is not known if a single cell produces multiple sub-classes of MVs or only one class at a time $(39,55)$. The size of TNAP proteoliposomes reconstituted from DPPC was $300 \mathrm{~nm}$, as determined by dynamic light scattering (53), and thus is comparable to the median size of natural MVs (39) and can adequately serve as a vesicular mimetic system to examine TNAP function in the context of a lipid membrane environment that mimics the MV environment. Electron microscopy of empty DPPC liposomes (Figure 2A) and TNAP-proteoliposomes (Figure 2B) showed that enzyme reconstitution does not affect the morphology of the liposomes.

Simão et al. (53) showed that the specific phospholipid microenvironment of MVs strongly influences the catabolism of the various physiological substrates of biomineralization by TNAP and NPP1, as well as their relative weight in catabolism. It further suggests that the mechanistic study of these enzymes and their pathological mutants in biomineralization would, therefore, be better conducted in relevant liposomes rather than in solution. Most previous work on MVs has focused on their disassembly to determine 

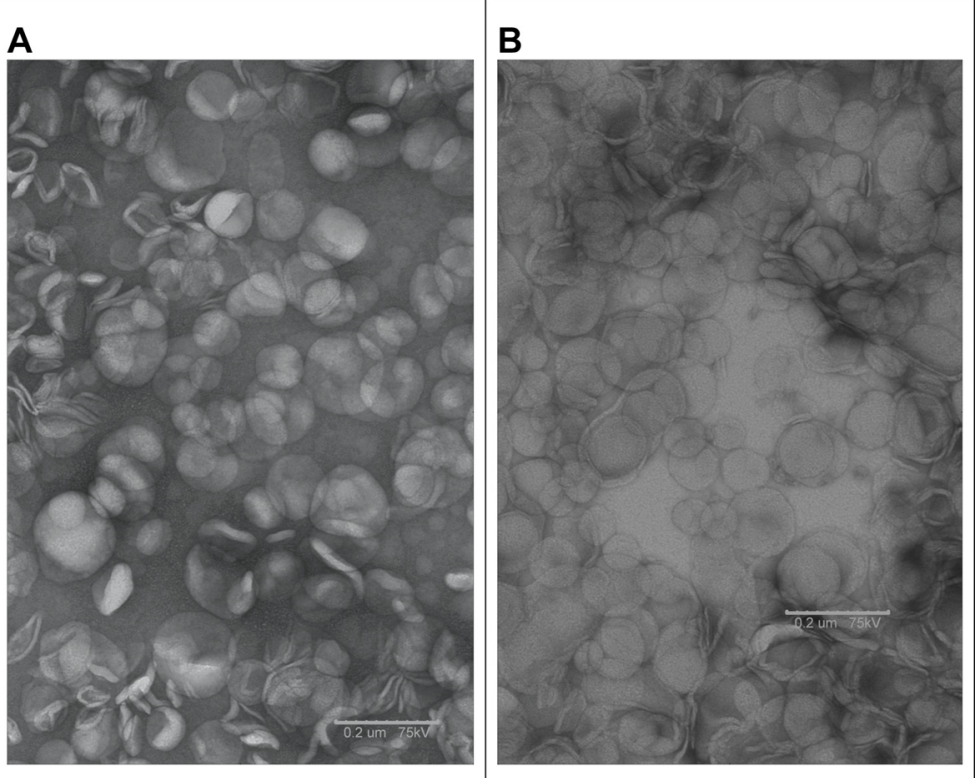

Figure 2. Electron microscopy using negative staining of: $A$, Liposomes consisting of dipalmitoylphosphatidylcholine (DPPC) and $B$, tissue-nonspecific alkaline phosphatase reconstituted in DPPC liposomes, both with magnification of 50X. A $5-\mu \mathrm{L}$ suspension of liposomes or proteoliposomes was placed on carbon-coated copper grids for $1 \mathrm{~min}$ to sediment the sample. The excess buffer was removed and exchanged for $2 \%(\mathrm{w} / \mathrm{v})$ of an aqueous solution of uranyl-acetate for $15 \mathrm{~s}$; excess uranyl-acetate was removed, grids were air-dried for 2-5 min and examined with a Hitachi H600A transmission electron microscope at $75 \mathrm{kV}$. Images were collected with an L9C cooled CCD, 11.2 megapixel camera (Special Achievement in innovation - SIA)

chemical composition, and on assays to elucidate how they function in mineralization. The proteoliposome system provides a means of reconstituting lipid vesicles that will function like MVs. There have been previous attempts to simulate MV mineralization using multilamellar liposomal systems $(44,45,56,57)$. More recently, liposomes containing various proportions of anionic and neutral phospholipids and cholesterol were used to study the ability of annexin $V$ to facilitate $\mathrm{Ca}^{2+}$ uptake (26). However, an accurate model of MVs must entail a unilamellar system closely approximating the size, lipid, electrolyte, and protein composition of native MVs that is capable of inducing mineralization.

\section{Proteoliposomes as MV biomimetics}

Such an MV biomimetic proteoliposome system would be useful for many important translational applications. The enzymatic defects associated with disease-causing mutations in the TNAP molecule, such as those found in hypophosphatasia (58) could be further elucidated in a membrane vesicle that better mimics their in vivo biological environment. Since this artificial vesicular system adequately mimics the kinetic behavior of the enzymes in the natural vesicular MV environment (53), this proteoliposome system can be used for the screening of small molecule compounds able to modulate (inhibit or activate) the activity of MV enzymes for potential therapeutic uses $(59,60)$. Such an approach seems indicated, especially when these compounds bear organic moieties capable of interacting with membrane phospholipids, directly or indirectly via $\mathrm{Ca}^{2+}$ ions present in the mineralizing microenvironment. A liposome environment will mimic the phospholipid-modified availability of organic substrates, inhibitors and modulators to membrane-bound enzymes, thus allowing the study of enzyme catalysis in a more physiological manner than with solubilized enzymes.

This nascent in vitro experimental system will also allow the construction of progressively more complex proteoliposomes containing PHOSPHO1, $\mathrm{P}_{\mathrm{i}} \mathrm{T} 1 / 2$, ANK, annexins, etc. that closely simulate the lipid, size, electrolyte, and protein composition of native MVs, and that also reproduce the kinetic properties of native MV in the formation of calcium phosphate minerals, with the ultimate goal of replicating in vitro the key events leading to the initiation of HA crystal formation in chondrocyte- and osteoblast-derived MVs. Once the proteoliposomes have been built and characterized, these vesicles can be added to fixed amounts of MVs, wild-type or deficient in specific enzymes, as a way of modulating their in vitro calcification properties. Those experiments would validate the use of these nanovesicles in promoting or delaying calcification, and such an artificial nanovesicular system could also potentially prove useful for the repair/treatment of craniofacial and other skeletal defects and to facilitate the mineralization of titanium-based tooth implants.

\section{Acknowledgments}

Research supported by grants \#DE12889, \#AR47908 and \#AR53102 from the National Institutes of Health, USA, and by FAPESP, CNPq and CAPES in Brazil. 


\section{References}

1. Glimcher MJ. Bone: nature of the calcium phosphate crystals and cellular, structural, and physical chemical mechanisms in their formation. Rev Mineral Geochem 2006; 64: 223282.

2. Anderson HC, Garimella R, Tague SE. The role of matrix vesicles in growth plate development and biomineralization. Front Biosci 2005; 10: 822-837.

3. Giachelli CM. Inducers and inhibitors of biomineralization: lessons from pathological calcification. Orthod Craniofac Res 2005; 8: 229-231.

4. Wu LN, Genge BR, Kang MW, Arsenault AL, Wuthier RE. Changes in phospholipid extractability and composition accompany mineralization of chicken growth plate cartilage matrix vesicles. J Biol Chem 2002; 277: 5126-5133.

5. Terkeltaub RA. Inorganic pyrophosphate generation and disposition in pathophysiology. Am J Physiol Cell Physiol 2001; 281: C1-C11.

6. Ho AM, Johnson MD, Kingsley DM. Role of the mouse ank gene in control of tissue calcification and arthritis. Science 2000; 289: 265-270.

7. Hessle L, Johnson KA, Anderson HC, Narisawa S, Sali A, Goding JW, et al. Tissue-nonspecific alkaline phosphatase and plasma cell membrane glycoprotein-1 are central antagonistic regulators of bone mineralization. Proc Natl Acad Sci U S A 2002; 99: 9445-9449.

8. Harmey D, Hessle L, Narisawa S, Johnson KA, Terkeltaub R, Millan JL. Concerted regulation of inorganic pyrophosphate and osteopontin by akp2, enpp1, and ank: an integrated model of the pathogenesis of mineralization disorders. $\mathrm{Am}$ J Pathol 2004; 164: 1199-1209.

9. Golub EE. Role of matrix vesicles in biomineralization. Biochim Biophys Acta 2009; 1790: 1592-1598.

10. Arispe N, Rojas E, Genge BR, Wu LN, Wuthier RE. Similarity in calcium channel activity of annexin $\mathrm{V}$ and matrix vesicles in planar lipid bilayers. Biophys $J$ 1996; 71: 1764-1775.

11. Wu LN, Sauer GR, Genge BR, Valhmu WB, Wuthier RE. Effects of analogues of inorganic phosphate and sodium ion on mineralization of matrix vesicles isolated from growth plate cartilage of normal rapidly growing chickens. J Inorg Biochem 2003; 94: 221-235.

12. Wuthier RE, Wu LN, Sauer GR, Genge BR, Yoshimori T, Ishikawa Y. Mechanism of matrix vesicle calcification: characterization of ion channels and the nucleational core of growth plate vesicles. Bone Miner 1992; 17: 290-295.

13. Kirsch $T$, Ishikawa $Y$, Mwale F, Wuthier RE. Roles of the nucleational core complex and collagens (types II and $X$ ) in calcification of growth plate cartilage matrix vesicles. J Biol Chem 1994; 269: 20103-20109.

14. Wu LN, Genge BR, Sauer GR, Wuthier RE. Characterization and reconstitution of the nucleational complex responsible for mineral formation by growth plate cartilage matrix vesicles. Connect Tissue Res 1996; 35: 309-315.

15. Balcerzak M, Malinowska A, Thouverey C, Sekrecka A, Dadlez $M$, Buchet $R$, et al. Proteome analysis of matrix vesicles isolated from femurs of chicken embryo. Proteomics 2008; 8: 192-205.

16. Xiao Z, Camalier CE, Nagashima K, Chan KC, Lucas DA, de la Cruz MJ, et al. Analysis of the extracellular matrix vesicle proteome in mineralizing osteoblasts. J Cell Physiol 2007;
210: 325-335.

17. Xiao Z, Blonder J, Zhou M, Veenstra TD. Proteomic analysis of extracellular matrix and vesicles. J Proteomics 2009; 72 : 34-45.

18. Millán JL. Mammalian alkaline phosphatases. From biology to applications in medicine and biotechnology. Weinheim: Wiley-VCH Verlag GmbH \& Co.; 2006.

19. Whyte MP. Hypophosphatasia. In: Scriver CR, Beaudet AL, Sly WS, Valle D (Editors), The metabolic and molecular bases of inherited disease. 7th edn. New York: McGraw-Hill; 1995. p 4095-4112.

20. Anderson HC, Hsu HH, Morris DC, Fedde KN, Whyte MP. Matrix vesicles in osteomalacic hypophosphatasia bone contain apatite-like mineral crystals. Am J Pathol 1997; 151: 1555-1561.

21. Anderson HC, Sipe JB, Hessle L, Dhanyamraju R, Atti E, Camacho NP, et al. Impaired calcification around matrix vesicles of growth plate and bone in alkaline phosphatasedeficient mice. Am J Pathol 2004; 164: 841-847.

22. Murshed M, Harmey D, Millan JL, McKee MD, Karsenty G. Unique coexpression in osteoblasts of broadly expressed genes accounts for the spatial restriction of ECM mineralization to bone. Genes Dev 2005; 19: 1093-1104.

23. Meyer JL. Studies on matrix vesicles isolated from chick epiphyseal cartilage. Association of pyrophosphatase and ATPase activities with alkaline phosphatase. Arch Biochem Biophys 1984; 231: 1-8.

24. Roberts S, Narisawa S, Harmey D, Millan JL, Farquharson C. Functional involvement of PHOSPHO1 in matrix vesiclemediated skeletal mineralization. J Bone Miner Res 2007; 22: 617-627.

25. Roberts SJ, Stewart AJ, Sadler PJ, Farquharson C. Human PHOSPHO1 exhibits high specific phosphoethanolamine and phosphocholine phosphatase activities. Biochem $J$ 2004; 382: 59-65.

26. Kirsch T, Nah HD, Demuth DR, Harrison G, Golub EE, Adams SL, et al. Annexin V-mediated calcium flux across membranes is dependent on the lipid composition: implications for cartilage mineralization. Biochemistry 1997; 36: 3359-3367.

27. Genge BR, Wu LN, Wuthier RE. Mineralization of annexin-5containing lipid-calcium-phosphate complexes: modulation by varying lipid composition and incubation with cartilage collagens. J Biol Chem 2008; 283: 9737-9748.

28. Kim HJ, Kirsch T. Collagen/annexin V interactions regulate chondrocyte mineralization. J Biol Chem 2008; 283: 1031010317.

29. Kavanaugh MP, Miller DG, Zhang W, Law W, Kozak SL, Kabat D, et al. Cell-surface receptors for gibbon ape leukemia virus and amphotropic murine retrovirus are inducible sodium-dependent phosphate symporters. Proc Natl Acad Sci U S A 1994; 91: 7071-7075.

30. Palmer G, Zhao J, Bonjour J, Hofstetter W, Caverzasio J. In vivo expression of transcripts encoding the Glvr-1 phosphate transporter/retrovirus receptor during bone development. Bone 1999; 24: 1-7.

31. Festing MH, Speer MY, Yang HY, Giachelli CM. Generation of mouse conditional and null alleles of the type III sodiumdependent phosphate cotransporter PiT-1. Genesis 2009; 
47: 858-863.

32. Wuthier RE. Lipids of matrix vesicles. Fed Proc 1976; 35 : 117-121.

33. Boyan BD, Schwartz Z, Swain LD, Khare A. Role of lipids in calcification of cartilage. Anat Rec 1989; 224: 211-219.

34. Genge BR, Wu LN, Wuthier RE. Identification of phospholipid-dependent calcium-binding proteins as constituents of matrix vesicles. J Biol Chem 1989; 264: 10917-10921.

35. Skrtic D, Eanes ED. Membrane-mediated precipitation of calcium phosphate in model liposomes with matrix vesiclelike lipid composition. Bone Miner 1992; 16: 109-119.

36. Genge BR, Wu LN, Wuthier RE. Kinetic analysis of mineral formation during in vitro modeling of matrix vesicle mineralization: effect of annexin A5, phosphatidylserine, and type II collagen. Anal Biochem 2007; 367: 159-166.

37. Hooper NM. Detergent-insoluble glycosphingolipid/cholesterol-rich membrane domains, lipid rafts and caveolae (review). Mol Membr Biol 1999; 16: 145-156.

38. Brown DA, London E. Structure and function of sphingolipidand cholesterol-rich membrane rafts. J Biol Chem 2000; 275: 17221-17224

39. Ciancaglini P, Simao AM, Camolezi FL, Millan JL, Pizauro JM. Contribution of matrix vesicles and alkaline phosphatase to ectopic bone formation. Braz J Med Biol Res 2006; 39: 603-610.

40. Camolezi FL, Daghastanli KR, Magalhaes PP, Pizauro JM, Ciancaglini P. Construction of an alkaline phosphataseliposome system: a tool for biomineralization study. Int $J$ Biochem Cell Biol 2002; 34: 1091-1101.

41. lerardi DF, Pizauro JM, Ciancaglini P. Erythrocyte ghost cell-alkaline phosphatase: construction and characterization of a vesicular system for use in biomineralization studies. Biochim Biophys Acta 2002; 1567: 183-192.

42. Blandford NR, Sauer GR, Genge BR, Wu LN, Wuthier RE. Modeling of matrix vesicle biomineralization using large unilamellar vesicles. J Inorg Biochem 2003; 94: 14-27.

43. Sesana S, Re F, Bulbarelli A, Salerno D, Cazzaniga E, Masserini M. Membrane features and activity of GPI-anchored enzymes: alkaline phosphatase reconstituted in model membranes. Biochemistry 2008; 47: 5433-5440.

44. Eanes ED, Hailer AW. Liposome-mediated calcium phosphate formation in metastable solutions. Calcif Tissue Int 1985; 37: 390-394.

45. Eanes ED. Biophysical aspects of lipid interaction with mineral: liposome model studies. Anat Rec 1989; 224: 220225.

46. Carruthers A, Melchior DL. How bilayer lipids affect membrane protein activity. TIBS 1986; 11: 331-335.

47. New RRC. Liposomes: a practical approach. New York:
Oxford University Press; 1990.

48. Prasad R. Manual of membrane lipids. Berlin-Heidelderg: Springer-Verlag; 1996.

49. Milhiet PE, Giocondi MC, Baghdadi O, Ronzon F, Roux $B$, Le Grimellec C. Spontaneous insertion and partitioning of alkaline phosphatase into model lipid rafts. EMBO Rep 2002; 3: 485-490.

50. Morandat S, Bortolato M, Roux B. Cholesterol-dependent insertion of glycosylphosphatidylinositol-anchored enzyme. Biochim Biophys Acta 2002; 1564: 473-478.

51. Kahya N, Brown DA, Schwille P. Raft partitioning and dynamic behavior of human placental alkaline phosphatase in giant unilamellar vesicles. Biochemistry 2005; 44: 74797489.

52. Santos HL, Rigos CF, Ciancaglini P. Kinetics behaviors of $\mathrm{Na}, \mathrm{K}-\mathrm{ATP}$ ase: comparison of solubilized and DPPC:DPPEliposome reconstituted enzyme. Comp Biochem Physiol C Toxicol Pharmacol 2006; 142: 309-316.

53. Simao AM, Yadav MC, Narisawa S, Bolean M, Pizauro JM, Hoylaerts MF, et al. Proteoliposomes harboring alkaline phosphatase and nucleotide pyrophosphatase as matrix vesicles biomimetics. J Biol Chem 2010 (ahead of print; doi: 10.1074/jbc.M109.079830).

54. Ciancaglini P, Yadav MC, Sper Simao AM, Narisawa S, Pizauro JM, Farquharson C, et al. Kinetic analysis of substrate utilization by native and TNAP-, NPP1- or PHOSPHO1-deficient matrix vesicles. J Bone Miner Res 2009 (ahead of print; doi: 10.1359/jbmr.091023).

55. Sela J, Gross UM, Kohavi D, Shani J, Dean DD, Boyan BD, et al. Primary mineralization at the surfaces of implants. Crit Rev Oral Biol Med 2000; 11: 423-436.

56. Eanes ED, Hailer AW, Costa JL. Calcium phosphate formation in aqueous suspensions of multilamellar liposomes. Calcif Tissue Int 1984; 36: 421-430.

57. Eanes ED, Hailer AW. Calcium phosphate precipitation in aqueous suspensions of phosphatidylserine-containing anionic liposomes. Calcif Tissue Int 1987; 40: 43-48.

58. Di Mauro S, Manes T, Hessle L, Kozlenkov A, Pizauro JM, Hoylaerts MF, et al. Kinetic characterization of hypophosphatasia mutations with physiological substrates. J Bone Miner Res 2002; 17: 1383-1391.

59. Sergienko E, Su Y, Chan X, Brown B, Hurder A, Narisawa $S$, et al. Identification and characterization of novel tissuenonspecific alkaline phosphatase inhibitors with diverse modes of action. J Biomol Screen 2009; 14: 824-837.

60. Lanier M, Sergienko S, Simao AMS, Chung T, Millán JL, Cashman JR. Design and synthesis of selective inhibitors of placental alkaline phosphatase. Bioorg Med Chem 2010; 18: $573-579$. 